\title{
REAÇÕES ORGÂNICAS EM MEIO AQUOSO
}

Flavia Martins da Silva e Joel Jones Jr*

Departamento de Química Orgânica, Instituto de Química, Universidade Federal do Rio de Janeiro, CP 68545, 21945-970 Rio de Janeiro - RJ

Recebido em 21/7/00; aceito em 13/12/00

\begin{abstract}
ORGANIC REACTIONS IN AQUEOUS MEDIA. The use of water as solvent in organic reactions has been uncommon for several reasons, among them the low solubility of the reactants, the incompatibility of the intermediates with water, and the competition between the desired reaction and hydrolysis. Breslow in 1980, demonstrated that the hydrophobic effect accelerates Diels-Alder reactions and gives a high endo/exo selectivity. Since then, many other reactions were studied in this medium, and below we show the principal results. Besides the academic interest, human and economic aspects are included in this study. Water as a solvent minimizes environmental impact, costs and increases operational safety.
\end{abstract}

Keywords: water; organic reactions; hydrophobic effect.

\section{INTRODUÇÃO}

A utilização de água como solvente costumava ser descartada dos estudos de reações orgânicas por diversas razões, entre elas, a insolubilidade dos reagentes, a incompatibilidade dos intermediários com a água e a competição das reações desejadas com processos de hidrólise dos reagentes ${ }^{1,2}$. No entanto, um dos principais problemas na indústria química está relacionado com a utilização de solventes orgânicos em seus processos. Sua manufatura, transporte, estoque, manuseio e descarte são aspectos que demandam muito cuidado e dinheiro. Por estes motivos, a substituição de solventes orgânicos como meio reacional por água é de grande interesse no que diz respeito a síntese orgânica, visto que minimiza o impacto ambiental, além de ter mais baixo custo e apresentar menor periculosidade operacional.

Em adição aos aspectos econômicos e humanos, a água apresenta muitas propriedades físico-químicas que podem ser úteis nas reações, como a alta polaridade, à capacidade de solvatar íons, formar ligações hidrogênio, ser um líquido estruturado, e agregar moléculas apolares dissolvidas (efeito hidrofóbico) $)^{1,3,4,5}$.

\section{ESTRUTURA DA ÁGUA}

Um solvente não pode ser considerado apenas por suas características contínuas macroscópicas, ou seja, constantes físicas como densidade, constante dielétrica, índice de refração, entre outras, mas também devem ser levadas em consideração características descontínuas, que consistem nas interações entre moléculas de solventes. De acordo com a extensão destas interações, os líquidos podem ser divididos em dois grupos: nãoestruturados e estruturados ou regulares. No primeiro, as moléculas permanecem juntas por forças fracas não-direcionais de van der Waals. No segundo grupo, onde a água se encaixa, as moléculas permanecem unidas por forças fortes e direcionais, como as ligações hidrogênio. Nos líquidos estruturados, as moléculas não preenchem todo o espaço de forma eficaz, e como conseqüência sua estrutura possui cavidades ${ }^{1,3}$.

A estrutura da água e sua importância ainda são objeto de muitos trabalhos na literatura. De forma geral, a água líquida é representada tanto por regiões ligadas de maneira ordenada,

*e-mail: jjones@ufrj.br quanto por regiões ligadas de forma aleatória por ligações hidrogênio. Esta estrutura pode ainda, ser entremeada por moléculas de água livre, cavidades e vacâncias ${ }^{3}$.

Em um segundo estágio, a água líquida é representada por um equilíbrio entre água estruturada e não-estruturada. Este equilíbrio, por sua vez, pode ser afetado por temperatura, pressão e aditivos. À temperatura e pressão normal, as moléculas de água em um líquido puro tem em média 4,4 vizinhos como constatado por difração de nêutrons ${ }^{1}$.

\section{REATIVIDADE DE COMPOSTOS APOLARES EM ÁGUA}

Efeitos de solventes na velocidade de uma reação podem ser entendidos em termos da teoria do estado de transição. Um aumento da constante de velocidade devido a um fator entálpico pode resultar de um aumento de entalpia do estado inicial, ou de um decréscimo de entalpia do estado de transição. De acordo com esta teoria, solventes podem modificar a energia de ativação pela diferente solvatação de reagentes e estado de transição ${ }^{1,3}$.

Dessa forma, as conhecidas reações de solvólise $S_{N} 1$ são aceleradas em solventes mais polares, como a água, devido as fortes interações entre o solvente e o estado de transição que leva a formação íon carbênio ${ }^{1,3}$. Por outro lado, devido às interações hidrofóbicas, temos que ter em mente que o fator entrópico também tem papel especial.

Rideout e Breslow, em 1980, foram os primeiros a apontarem a importância deste efeito em reações orgânicas. Seu trabalho mostrou que reações do tipo Diels-Alder são muito aceleradas em água, embora pouco sensíveis à polaridade do meio ${ }^{4}$. Uma explicação para essa aceleração seria o efeito hidrofóbico que é a tendência de espécies apolares a se agregarem em água com reconstituição da estrutura original da água ${ }^{3}$. Entretanto, só esta associação não seria suficiente para explicar o aumento da constante de velocidade. Supõe-se que isto se deva à alta energia de coesão da água, cujas moléculas ligam-se mais eficientemente a elas mesmas do que a superfície hidrocarbônica e este efeito tende a diminuir a superfície de contato entre moléculas hidrofóbicas e a água. Este processo é facilitado pelo decréscimo do volume dos reagentes ao longo da coordenada de reação, e pode ser aumentado para reações com volume de ativação negativo. Tal hipótese é chamada de "interação hidrofóbica forçada". Como conseqüência, entre dois produtos possíveis em uma reação, aquele que passar por um estado de transição mais compacto, deverá ser o principal quando utilizarmos a água como solvente ${ }^{1}$. 


\section{REAÇÕES EM ÁGUA}

A partir de 1980, quando Rideout e Breslow ${ }^{4}$ publicaram o primeiro artigo evidenciando a importância e as vantagens de reações orgânicas promovidas em água, muitas outras reações foram estudadas nesse meio ${ }^{6,7,8}$, como: hetero Diels-Alder, ciclo-adições dipolares, rearranjos de Claisen, adições nucleofílicas (aldolização, adição tipo Michael, etc), reações do tipo Barbier, reações catalisadas por complexos de metais de transição, oxidações, reduções, clivagens autocatalíticas e estudos nos estados sub- e superaquecido.

\section{Reações Tipo Diels-Alder}

A reação tipo Diels-Alder foi a primeira estudada que demonstrou claramente um aumento de velocidade, devido aos fatores entrópicos, ao se utilizar água como solvente. $\mathrm{O}$ trabalho desenvolvido por Breslow descrevia o estudo cinético da cicloadição de ciclo-pentadieno com metilvinilcetona (Esquema 1), e mostrava que esta reação era 700 vezes mais rápida em água do que em isooctano. O efeito hidrofóbico atuante nesta reação é suportado pelo aumento de velocidade com a adição de sais como cloreto de lítio, que diminuem ainda mais a solubilidade de moléculas orgânicas em água ("salting-out"), além do decréscimo de velocidade da reação quando se usam sais como cloreto de guanidínio, que promovem um "salting-in",4,5.

Este processo mostra ainda uma alta seletividade para os produtos endo em relação aos demais solventes orgânicos ${ }^{4,5}$ e a reação pode, inclusive, ser feita em suspensão, que esta seletividade não é muito afetada ${ }^{10}$. Este resultado ilustra bem a teoria da "interação hidrofóbica forçada", formado a partir do estado de transição mais empacotado.

Ahamd-Zadeh estabelece que a alta polaridade não é responsável nem pelo aumento de velocidade, nem pelo aumento de seletividade, já que solventes ainda mais polares não causam o mesmo efeito (Esquema 2) ${ }^{9}$, reforçando a idéia da compressão no estado de transição. Foi constatado ainda que ácidos de Lewis, como nitrato de cobre, também podem ser usados para catalisar o processo ${ }^{11}$, exibindo a mesma endo seletividade.

Existem ainda, exemplos de reações intramoleculares em meio aquoso, como a mostrada no Esquema 3, levando a uma mistura diastereoisomérica dos produtos de ciclo-adição ${ }^{12-14}$.

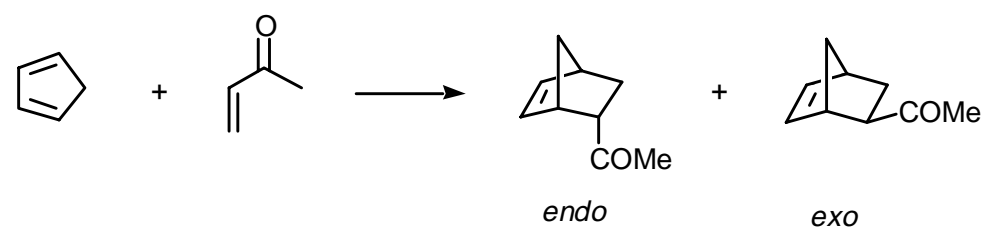

\begin{tabular}{l|c}
\hline \multicolumn{2}{c}{ Cinética } \\
\hline Solvente & $\begin{array}{c}\mathbf{1 0}^{\mathbf{5}} \mathbf{k}_{\mathbf{2}} \\
\left(\mathbf{m o l}^{\mathbf{1}} \mathbf{s}^{-1}\right)\end{array}$ \\
\cline { 2 - 2 } & 5,94 \\
isooctano & 75,5 \\
metanol & 4.400 \\
$\mathrm{H}_{2} \mathrm{O}$ & 10.800 \\
$\mathrm{H}_{2} \mathrm{O}+4,86 \mathrm{M} \mathrm{LiCl}$ & 4.300 \\
$\mathrm{H}_{2} \mathrm{O}+\left(\mathrm{NH}_{2}\right)_{3} \mathrm{CCl}$ & 4.06
\end{tabular}

\begin{tabular}{l|r}
\hline \multicolumn{2}{c}{ Seletividade } \\
\hline Solvente & endo / exo \\
\hline ciclo-pentadieno & 3,85 \\
etanol & 8,5 \\
$0,15 \mathrm{M} \mathrm{em} \mathrm{H}_{2} \mathrm{O}$ & 21,4 \\
$0,007 \mathrm{M} \mathrm{em} \mathrm{H} \mathrm{H}_{2} \mathrm{O}$ & 22,5
\end{tabular}

Esquema 1. Estudo cinético da reação de Diels-Alder de 2-butenona com ciclo-pentadieno.

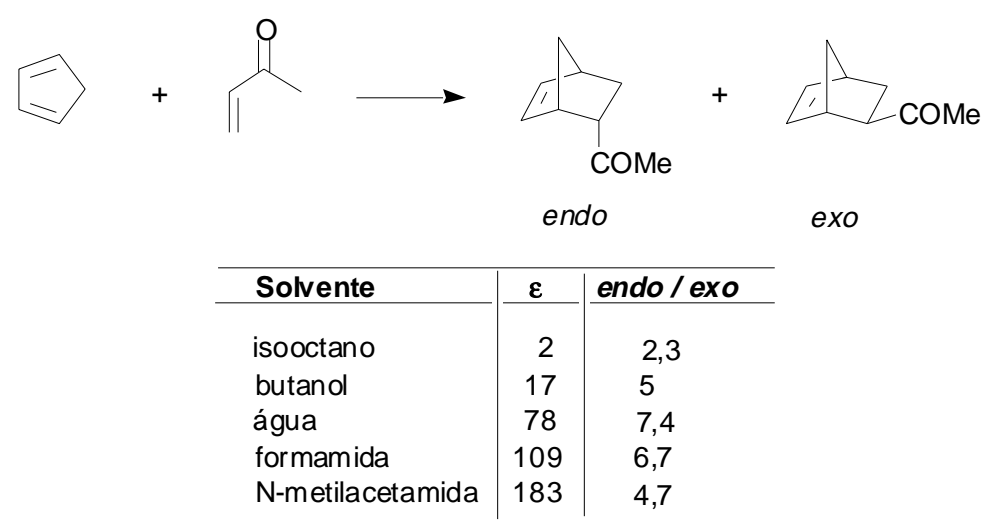

Esquema 2. Estudo da endo seletividade da reação de Diels-Alder com relação a polaridade do meio.

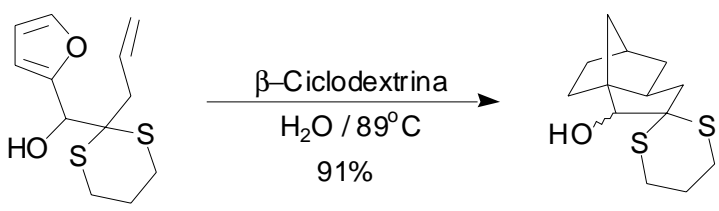

Esquema 3. Reação do tipo Diels-Alder intramolecular. 


\section{Adições Assimétricas}

Alguns exemplos de ciclo-adições assimétricas são relatados na literatura ${ }^{15,16}$. Podemos citar o uso de 4-hidróxi-2-ciclopentenona e seus derivados como equivalentes sintéticos quirais para ciclo-pentadienonas. É formada uma mistura diastereoisomérica dos produtos endo com seletividade anti, que quando tratados com base, levam a uma mistura de enantiômeros em uma razão proporcional à obtida na ciclização para a formação dos diastereoisômeros anti/sin ${ }^{15}$ (Esquema 4).

A indução assimétrica também pode ser feita com dienos acíclicos assimétricos. A reação da metacroleína com um dieno carboxilado quiral leva aos produtos (1) e (2) em uma razão de $5 / 1$ (Esquema 5) ${ }^{16}$.

\section{Reações Hetero Diels-Alder}

Larsen e Grieco foram os primeiros a estudar reações hetero
Diels-Alder em meio aquoso ${ }^{17}$. Eles descreveram a reação de ciclo-adição de sais de imínio, gerados in situ nas condições de Mannich, com diversos dienos (Esquema 6) ${ }^{17}$.

Também demonstram o potencial para indução assimétrica deste tipo de reação em água utilizando cloreto de (-)- $\alpha$ metil-benzamina ${ }^{17}$.

Uma extensão interessante desta metodologia foi usada por Waldman utilizando os hidrocloretos de ésteres de $(R) \mathrm{e}$ $(S)$-amino-ácidos como indutores quirais em processos de aza Diels-Alder. A utilização do auxiliar $(S)$ resulta seletivamente em uma configuração $(1 R, 4 S)$ do produto bicíclico, enquanto que o éster do $(R)$-amino-ácido produz uma estereoquímica $(1 S, 4 R)$ para os carbonos cabeça de ponte (Esquema 7$)^{18,19}$.

Lubineau, Augé e Lubin $^{20}$ estudaram processos de oxoDiels-Alder reagindo, simplesmente, solução aquosa comercial de ácido glioxálico com ciclo-pentadieno para produzir $\alpha$ hidróxi- $\gamma$-lactonas (Esquema 8).

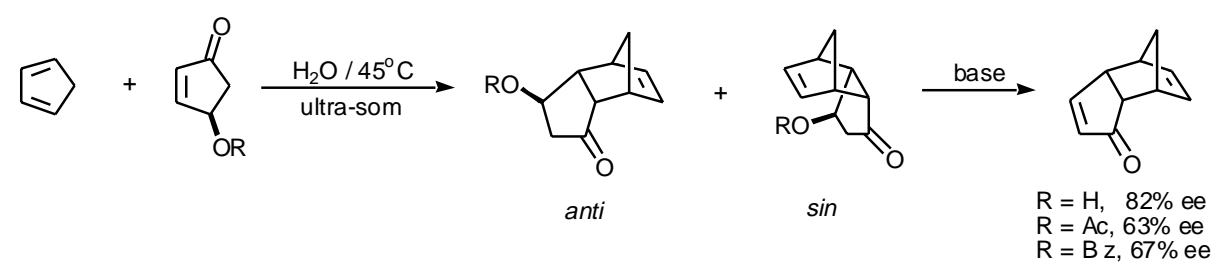

Esquema 4. Uso de 4-hidroxi-2-ciclo-pentenona com equivalentes sintético quiral para ciclo-pentadienonas.

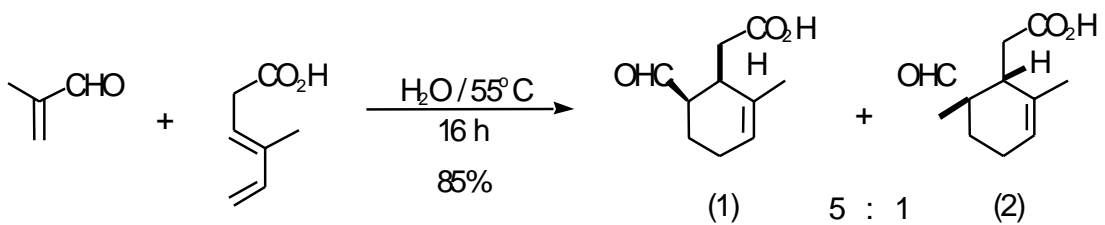

Esquema 5. Indução assimétrica em reação do tipo Diel-Alder por um dieno acíclico assimétrico.
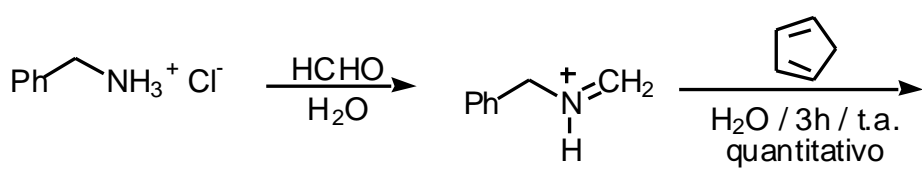<smiles></smiles>

Esquema 6. Reação hetero Diels-Alder - sal de iminium com ciclo-butadieno

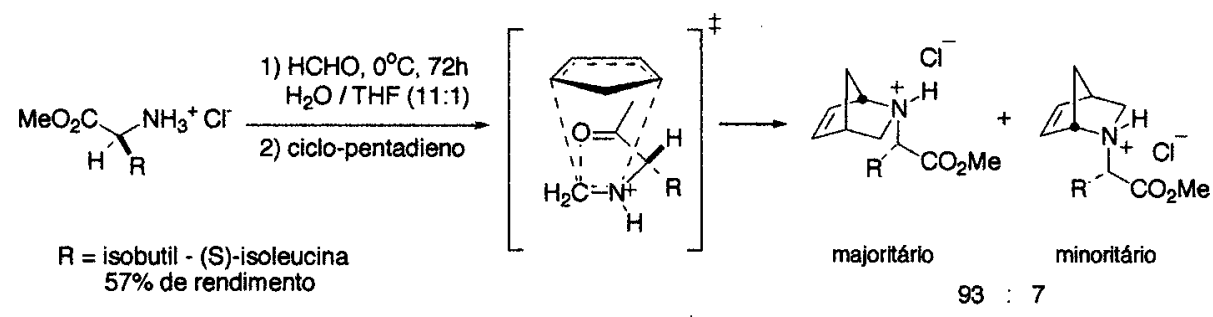

Esquema 7. Utilização de aminoácidos como indutores assimétricos em reações hetero Diels-Alder.

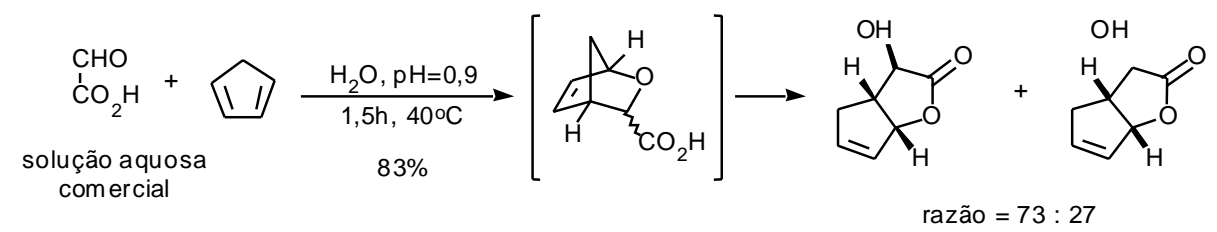

Esquema 8. Obtenção de $\alpha$-hidroxi- $\gamma$-lactonas a partir de uma reação oxo-Diel-Alder. 


\section{Adições 1,3-Dipolar}

Ciclizações 1,3-dipolares de óxidos de nitrila com dipolarófilos podem ser realizadas em sistema aquosos bifásicos. O óxido de nitrila é normalmente gerado in situ pela oxidação de oximas. Esta metodologia, quando aplicada ao limoneno, é regio- e quimioespecífica na ligação dupla 8,9 , produzindo isoxazolinas diastereoisoméricas (Esquema 9) ${ }^{21}$.

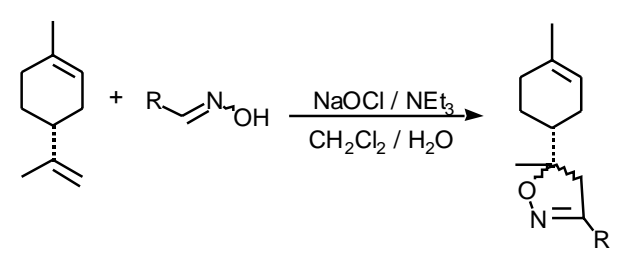

Esquema 9. Ciclo-adição de óxidos de nitrila ao limoneno.

Estudos sobre os efeitos de solventes neste tipo de reação, mostraram novamente uma aceleração em meio aquoso que parece ser induzida pelo efeito hidrofóbico (Esquema 10$)^{22,23}$.

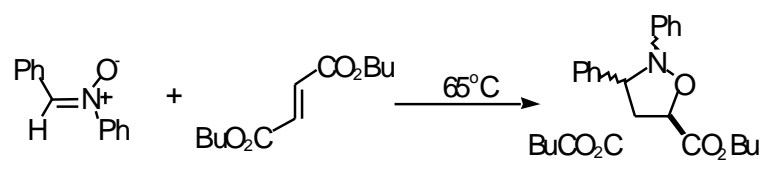

\begin{tabular}{l|c}
\hline Solvente & $\mathbf{1 0}^{\mathbf{4}} \mathbf{k}_{\mathbf{2}} / \mathbf{d \mathbf { c m }} \mathbf{m o l}^{\mathbf{1}} \mathbf{s}^{-1}$ \\
\hline n-hexano & 19,4 \\
THF & 5,9 \\
etanol & 1,9 \\
água & 237 \\
água (2MLCl) & 985 \\
água (2Muréia) & 142 \\
etileno glicol & 34
\end{tabular}

Esquema 10. Efeito hidrofóbico em reações de ciclo-adição de $N$-difenilnitronas.

Uma aplicação importante de ciclizações 1,3-dipolar em água, está na síntese da (+)-biotina e seus derivados benzilados a partir de uma azida (Esquema 11). Neste caso é necessário utilizar água no estado superaquecido, área de estudo que tem atraído muita atenção ${ }^{24}$.

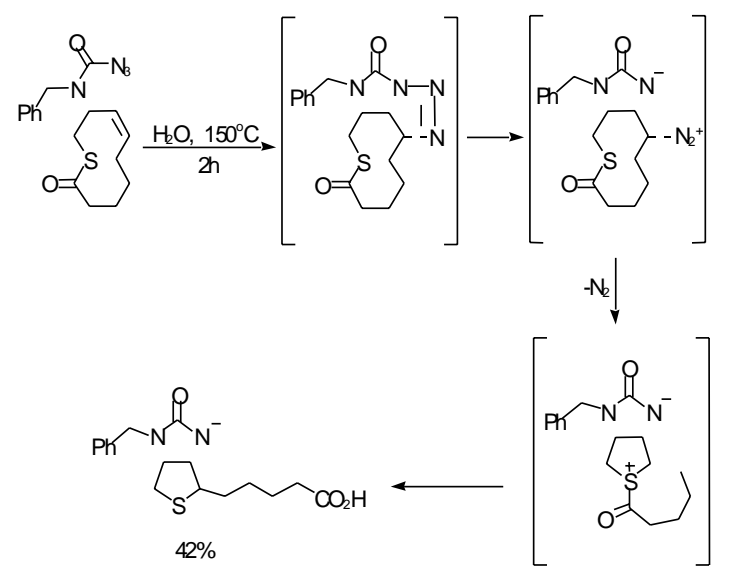

Esquema 11. Obtenção de (+)-N-benzil-biotina em água superaquecida.

\section{Rearranjo de Claisen}

Rearranjos sigmatrópicos do tipo Claisen também, têm suas constantes de velocidades aumentadas em água. Devido ao seu volume de ativação negativo, é esperado que o efeito hidrofóbico possa ser um dos responsáveis por este fato ${ }^{1}$.

O rearranjo de clorismato para prefenato em água pura é 100 vezes mais rápido do que em metanol (Esquema 12) ${ }^{25}$.
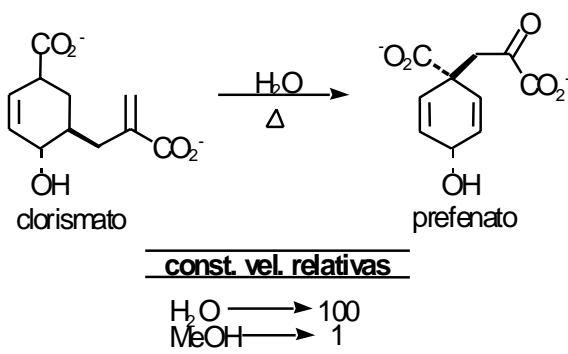

Esquema 12. Rearranjo de Claisen do clorismato em água.

Um alilviniléter contendo um grupo carboxilato na forma de sal sofre um rearranjo [3,3]-sigmatrópico em água para produzir um aldeído (Esquema 13). A reação é 23 vezes mais rápida em água que em metanol ${ }^{26}$.

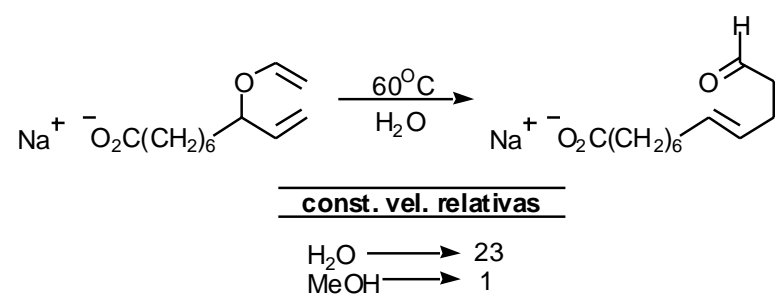

Esquema 13. Rearranjo de Claisen de um alil-vinil-éter.

Tentativas de realizar a síntese de compostos do tipo fenestreno com junção trans entre os anéis adjacentes não obtiveram sucesso ${ }^{27}$. Entretanto, no Esquema 14 é mostrado um típico Rearranjo de Claisen só que em solução aquosa de metanol (3:1) onde a junção de anel trans é obtida em $48 \%$ de rendimento 28 .

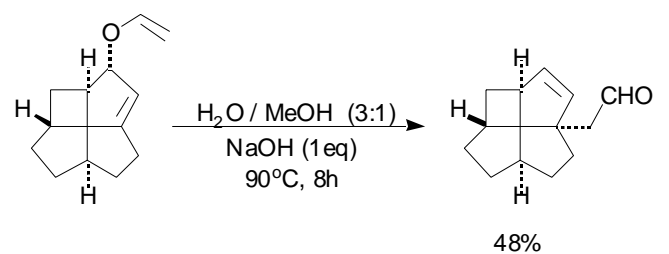

Esquema 14. Rearranjo de Claisen do fenestreno em solução aquosa de metanol (3:1).

O grupo de Lubineau tem estudado extensivamente a utilização de açúcares como indutores de quiralidade em reações em meio aquoso. Entre estes trabalhos, pode-se citar a utilização de glucose em rearranjos de Claisen que levam a um moderado excesso diastereoisomérico. No entanto, os diastereoisômeros cristalinos podem ser separados facilmente. (Esquema 15) ${ }^{29}$.

\section{Reações Tipo Barbier-Grignard}

Na reação do tipo Barbier-Grignard, um composto organometálico age como nucleófilo adicionando a uma carbonila. A 


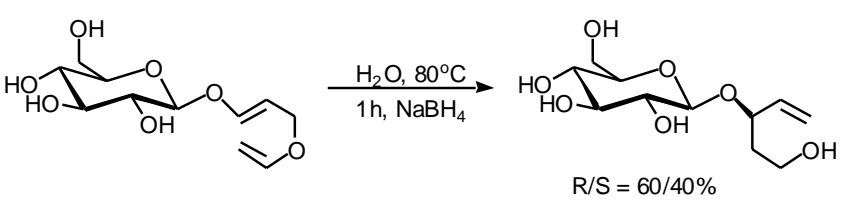

Esquema 15. Utilização de glucose em rearranjos de Claisen.

geração do organometálico pode ser feita in situ, como foi feito por Barbier, ou pode ser feita em uma etapa antes da adição do composto carbonilado, como feito por Grignard. O maior requisito, nestes casos, é a ausência completa de umidade e hidrogênios ácidos na molécula, visto que estes intermediários organometálicos são bases e podem abstrair estes prótons ${ }^{30}$.

Em 1983, Nokami e colaboradores observaram uma aceleração da reação de alilação de benzaldeído com dibrometo de dialil-estanho pela adição de água à mistura reacional. Este fato os inspirou a estudar este tipo de reação em meio aquoso. As melhores condições reacionais observadas utilizam um meio heterogêneo, cujo solvente trata-se de um mistura de éter e solução aquosa ácida. Além de ácido, outros aditivos que podem ser utilizados na alilação de cetonas ou aldeídos menos reativos são alumínio, estanho, zinco e índio metálico ${ }^{30}$.

Uma extensão importante desta metodologia, está nas reações intramoleculares de cetonas que possuem em sua estrutura um haleto alílico (Esquema 16) ${ }^{30}$.

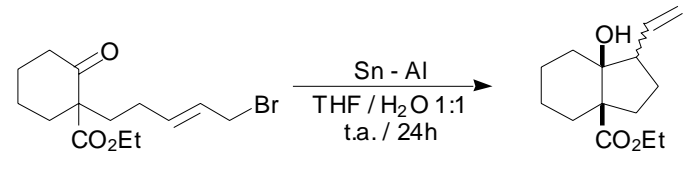

$81 \%$

Esquema 16. Reação de Barbier intramolecular utilizando SnAl como mediador.

Alilação de açúcares pode ser feita em água / etanol sem necessidade de proteger as hidroxilas. A reação ocorre com utilização de ultra-som e observa-se uma diastereosseletividade treo (Esquema 17) ${ }^{31}$.

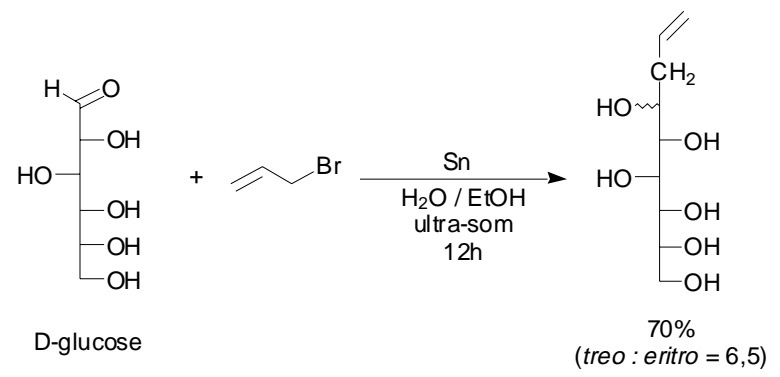

Esquema 17. Alilação de D-glucose utilizando Sn como mediador.

Pétrier e Luche ${ }^{32}$ observaram que o uso de $\mathrm{Zn}$ em água saturada com cloreto de amônio aumenta a eficiência dos resultados, podendo a reação ser promovida na ausência de ultrasom (Esquema 18).

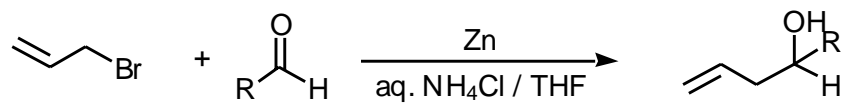

Esquema 18. Reação de Barbier utilizando Zn como mediador.
Em 1991, Li e Chan reportaram o uso de índio para mediar reações do tipo Barbier-Grinard em meio aquoso ${ }^{33}$. Neste caso, a reação ocorre com bons rendimentos sem necessidade de condições ácidas, aquecimento ou ultra-som. Um bom exemplo é a alquilação de metil-cetonas contendo grupos sensíveis como acetais (Esquema 19).

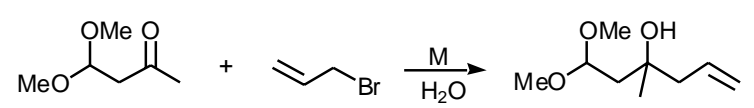

\begin{tabular}{l|l}
\hline Metal & rendimen to (\%) \\
\cline { 1 - 2 } In & 70 \\
Zn & 0 (destruição do reagente) \\
Sn & 10 (sob sonificação)
\end{tabular}

Esquema 19. Reação de Barbier utilizando In como mediador.

Mais recentemente foi demonstrado que alilações de compostos carbonílicos contendo grupos cetais, podem ser feitas utilizando tetraalil-estanhos como reagentes (Esquema 20) ${ }^{34}$.

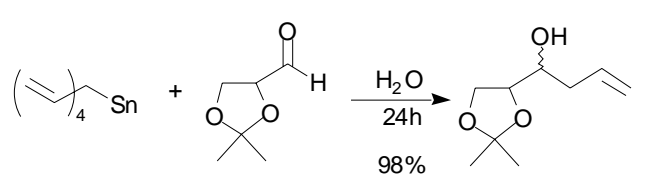

Esquema 20. Alteração de compostos carborilados contendo grupos sensíveis a ácidos por tetraalil-estanho.

O uso de magnésio para reação do tipo Barbier em meio aquoso foi reportado por Li e Zhang em $1998^{35}$. Em alguns casos observou-se a formação do produto de acoplamento pinacol e de álcool benzílico (Esquema 21).

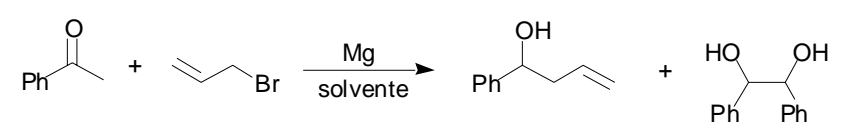

(3)

(4)

\begin{tabular}{l|c|c}
\hline Solvente & Mediador & (3)/(4)/álc. benzílico \\
\cline { 2 - 3 } THF: $\mathrm{H}_{2} \mathrm{O}(10: 0,55)$ & $\mathrm{Mg} / \mathrm{I}_{2}$ & $100 / 0 / 0$ \\
$0,1 \mathrm{~N} \mathrm{HCl}$ aquoso & $\mathrm{Mg} / \mathrm{I}_{2}$ & $28 / 66 / 6$ \\
$0,1 \mathrm{~N} \mathrm{NH}_{4} \mathrm{Cl}$ & $\mathrm{Mg}$ & $41 / 52 / 7$
\end{tabular}

Esquema 21. Reação de Barbier utilizando $\mathrm{Mg}$ como mediador.

Um outro aspecto interessante da reação de Barbier está sendo bastante estudado por Paquette e envolve a diastereosseletividade destas reações de alilação ${ }^{36,37}$. Um bom exemplo é a reação de 3-bromo-2-butenoato de metila com aldeídos contendo anéis piridínicos ou grupos carboxilados que leva a diferentes diastereosseletividades (Esquema 22) ${ }^{37}$.

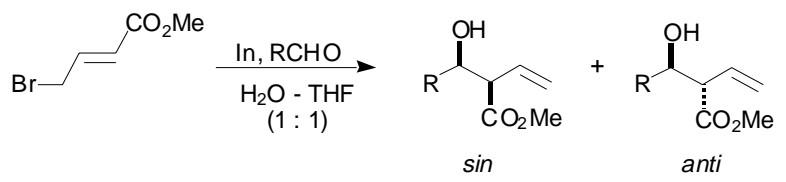

\begin{tabular}{l|l|c}
\hline \multicolumn{1}{c|}{$\mathbf{R}$} & sin / anti & Rend. (\%) \\
\hline 3-Py & $22 / 78$ & 62 \\
$2-\mathrm{Py}$ & $94 / 6$ & 81 \\
$\mathrm{CO}_{2} \mathrm{CH}_{3}$ & $88 / 12$ & 52
\end{tabular}

Esquema 22. Diastereosseletividade de reação de alilação. 
Um exemplo interessante do uso de um meio aquoso para reações orgânicas foi demonstrado por Yang e Chan ${ }^{38}$. Eles desenvolveram uma metodologia "one pot" para a síntese de estruturas tricíclicas através da adição de um organoíndio, seguida de ciclização do tipo Diels-Âlder (Esquema 23).

\section{Condensação Aldólica e Reações do Tipo Reformatsky}

As condensações de compostos carbonilados são muito importantes em síntese orgânica para formação de uma nova ligação carbono-carbono. Em sua versão mais simples, esta é realizada a partir dos substratos carbonilados sobre catálise básica ou ácida. No entanto, estes processos podem levar aos produtos de desidratação ou à polímeros. Além disto, produtos de condensação cruzada só podem ser obtidos com bons rendimentos se vierem da reação de um composto carbonilado não enolizável, por exemplo benzaldeído e derivados, com um outro menos reativo à reações de adição, para que funcionem bem como enolatos ${ }^{39}$.

Uma modificação útil desta metodologia para obtenção de produtos de condensação cruzada envolve a reação de um sililenoléter com um composto carbonilado (Reação de Mukaiyama) na presença de um ácido de Lewis $^{40}$. Recentemente, esta reação tem sido feita, com sucesso, em meio aquoso sob condições neutras, na presença de um ácido de Lewis (Esquema 24$)^{40-42}$.

Em 1999, Kobayashi ${ }^{43}$, mostrou o uso complexos quirais como catalisadores para induzir alguma quiralidade no produto de condensação (Esquema 25).

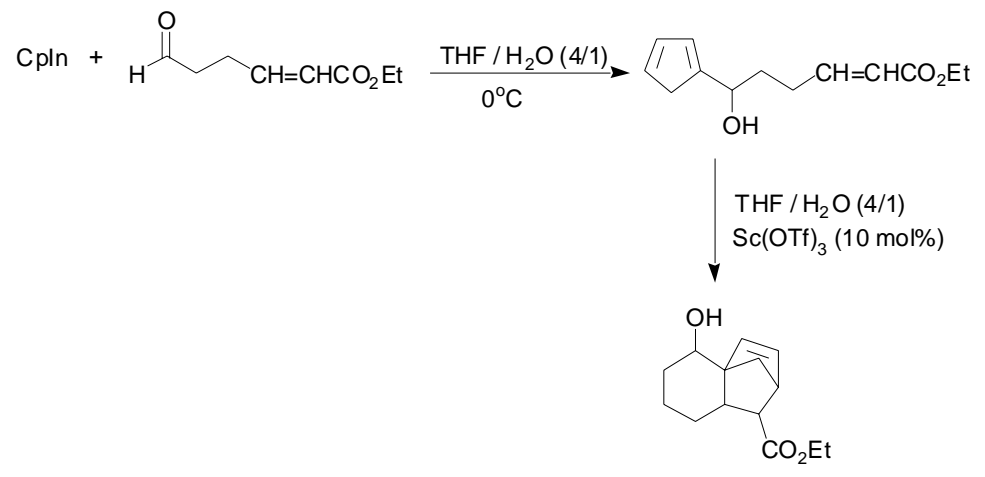

Esquema 23. Adição de organometálico seguida de reação de Diels-Alder "one pot".

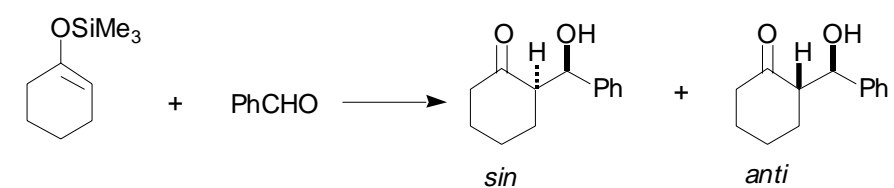

\begin{tabular}{|c|c|c|c|c|c|}
\hline Solvente & Temp. $\left({ }^{\circ} \mathrm{C}\right)$ & Tempo & Condições & Rend. (\%) & $\sin / a n t i$ \\
\hline $\mathrm{CH}_{2} \mathrm{Cl}_{2}$ & 20 & $2 \mathrm{~h}$ & 1eq $\mathrm{TiCl}_{4}$ & 82 & $25: 75$ \\
\hline $\mathrm{CH}_{2} \mathrm{Cl}_{2}$ & 60 & 9 dias & $10 \mathrm{kbar}$ & 90 & $75: 25$ \\
\hline $\mathrm{H}_{2} \mathrm{O}$ & 20 & 5 dias & agitação & 23 & $85: 15$ \\
\hline $\mathrm{H}_{2} \mathrm{O}-\mathrm{THF}(1: 1)$ & 20 & 5 dias & agitação & 45 & $74: 26$ \\
\hline $\mathrm{H}_{2} \mathrm{O}-\mathrm{THF}(1: 1)$ & 55 & 2 dias & ultra-som & 72 & $74: 26$ \\
\hline $\mathrm{MeOH}$ & 55 & 1 dias & ultra-som & 30 & $57: 43$ \\
\hline $\mathrm{H}_{2} \mathrm{O}-\mathrm{MeOH}(1: 1)$ & 55 & $1 \mathrm{dia}$ & ultra-som & 35 & $65: 35$ \\
\hline $\mathrm{H}_{2} \mathrm{O}-\mathrm{THF}(1: 4)$ & t.a & $20 \mathrm{~h}$ & $\mathrm{Yb}(\mathrm{OTf})_{3}$ & 91 & $73: 27$ \\
\hline
\end{tabular}

Esquema 24. Reação de Mukaiyama em água.

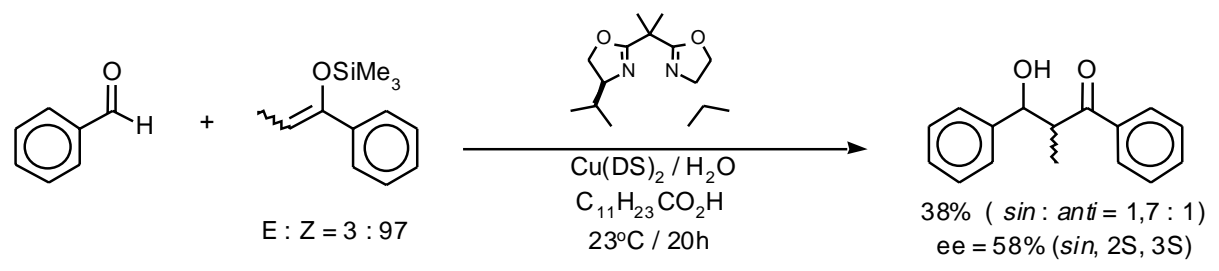

DS = dodecilsulfonato

Esquema 25. Catálise assimétrica na condensação de silil-enol-éter com benzaldeído. 


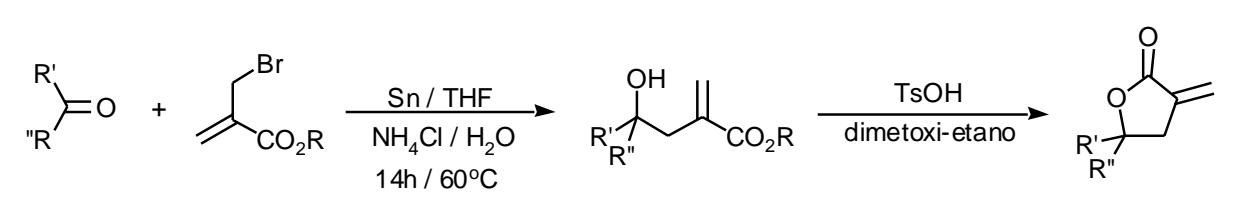

Esquema 26. Reação de Reformastky.<smiles>CC(=O)CC(O)c1ccc([N+](=O)[O-])cc1</smiles>

Esquema 27. Obtenção do produto de condensação aklólica com pH controlado.

Reações do tipo Reformastsky podem ser realizadas em água ou água / $\mathrm{THF}^{44-47}$, sendo útil na preparação de $\alpha$-metileno- $\gamma$ butirolactonas (Esquema 26).

Derivados de benzaldeído quando condensados com acetona produzem, mesmo em meio básico, a cetona $\alpha, \beta$ insaturada ${ }^{48}$. Entretanto, na presença de zinco com aminoésteres ou amino-álcoois como catalisadores, além de um bom controle do $\mathrm{pH}$ do meio reacional, a desidratação do produto de condensação aldólica pode ser evitada ${ }^{48}$ (Esquema 27). Por outro lado, Fringuelli e colaboradores reportaram a condensação de ciclo-hexanona com benzaldeído em solução de $\mathrm{NaOH}(0,25 \mathrm{M})$ na presença de um surfactante (cloreto de cetil-trimetilamônio $)^{49}$. Este último procedimento levou a $90 \%$ da hidróxi-cetona ${ }^{49}$.

Um fato muito interessante que demostra a grande complexidade das reações em fase aquosa é a condensação aldólica intramolecular do ceto-aldeído (4) que mostra uma alta diastereosseletividade anti quando catalisada por hidróxido de sódio e sin por ácido acético. Entretanto, quando foi utilizado $\mathrm{HCl}$ a diastereosseletividade pode variar com a quantidade do ácido ${ }^{50}$ (Esquema 28).

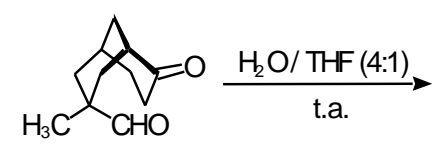

(4)

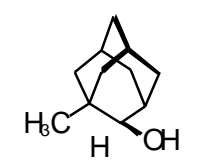

$\sin$

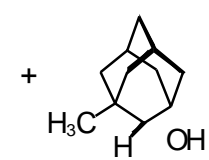

ant

\begin{tabular}{l|c|c}
\hline Ácido / Base & Tempo(h) & sin $/ a n t i$ \\
\hline $\mathrm{NaOH}$ & 1 & $16: 84$ \\
$\mathrm{CH}_{3} \mathrm{CO}_{2} \mathrm{H}$ & 3 & $87: 13$ \\
$\mathrm{HCl}(10$ eq) & 1 & $65: 35$ \\
$\mathrm{HCl}(0,01$ eq) & 1 & $91: 9$
\end{tabular}

Esquema 28. Condensação aldólica intramolecular.

Uma outra variação de condensação em água encontrada na literatura é a reação nitro-aldol catalisada por base na presença de um agente de transferência de fase (Esquema 29) ${ }^{51}$.

\section{Reação Tipo Michael}

A reação de adição de Michael é muito aplicada em síntese

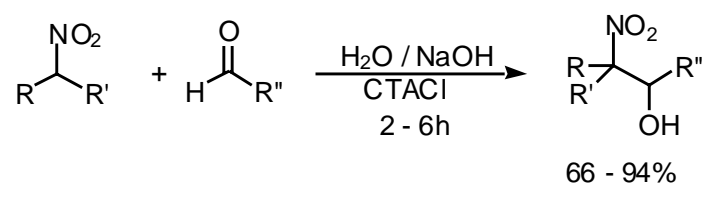

$\mathrm{CTACI}=$ cloreto de cetil-trimetil-amônio

Esquema 29. Nitro-aldol em meio aquoso.

orgânica, e tem importância relevante quando se trata de formação de uma nova ligação carbono-carbono ou na formação de compostos polifuncionais ${ }^{52}$.

Encontram-se alguns exemplares de reações de Michael em meio aquoso. Keller e Feringa estudaram a adição 1,4 de vários ceto-ésteres a aldeídos e cetonas $\alpha, \beta$-insaturadas ${ }^{53}$ e de $\alpha$-nitro-ésteres à metilvinilcetona ${ }^{54}$ (Esquema 30 ). A reação ocorre em meio aquoso, catalisada por ácidos de Lewis tolerantes a água como triflato de itérbio.

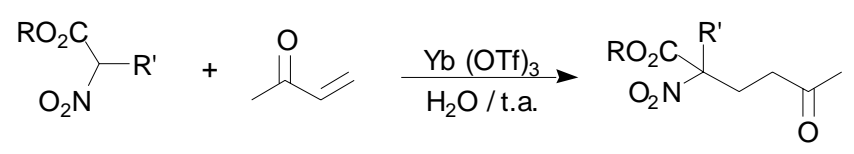

Esquema 30. Adição de Michael catalisada por ácidos de Lewis tolerantes a água.

Nitro-alcanos fazem o mesmo tipo de reação em meio aquoso, catalisada por hidróxido de sódio na presença de um agente de transferência de fase ${ }^{55}$. Lubineaou e Auge ect $^{56}$ publicaram o primeiro exemplo de adição de Michael de nitro-alcanos em água sem necessidade de catalisador. No entanto, este método parece ser efetivo apenas para eletrófilos muito reativos como metilvinilcetona (Esquema 31)

Em 1999, Jones e colaboradores demonstraram que a adição de nitro-alcanos, tióis e compostos dicarbonilados à 2-ciclo-hexenona podia ser realizada em água, em presença de base, sem necessidade de agentes de transferência de fase. No entanto, o $\mathrm{pH}$ do meio reacional é um parâmetro extremamente importante na otimização da metodologia. Além disto, o pH ótimo (aquele que leva a melhores rendimentos) depende do nucleófilo usado (Tabela 1$)^{57}$.
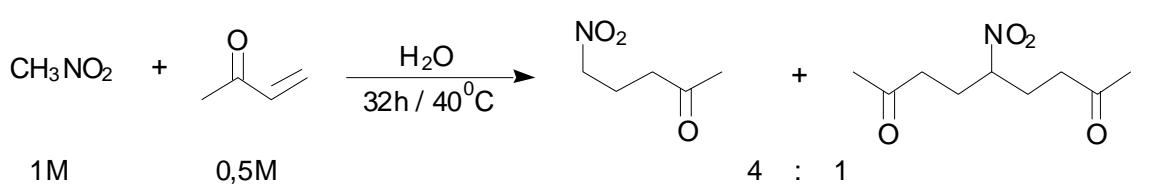

Esquema 31. Adição de Michael de nitro-metano a metil-vinil-cetona em condições neutras. 
Tabela 1. Reação de nitro-alcanos, compostos dicarbonilados e tióis a 2-ciclo-hexenona.

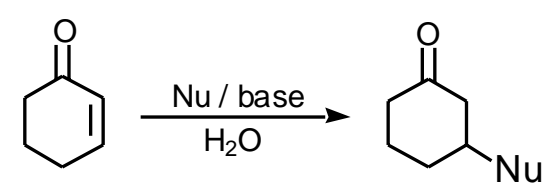

\begin{tabular}{|c|c|c|c|c|c|}
\hline $\mathrm{NuH}$ & pKa & $\mathrm{pH}$ & $\begin{array}{c}\text { Tempo } \\
\text { (h) }\end{array}$ & Produto & $\begin{array}{c}\text { Rend.' } \\
(\%)\end{array}$ \\
\hline $\mathrm{CH}_{3} \mathrm{NO}_{2}$ & 10,21 & $\begin{array}{l}\mathrm{NaOH}(\mathrm{pH}=14) \\
\mathrm{Na}_{2} \mathrm{CO}_{3}(\mathrm{pH}=10) \\
\mathrm{NaHCO}_{3}(\mathrm{pH}=7,5)\end{array}$ & 5,0 & & $\begin{array}{l}65 \\
40 \\
20\end{array}$ \\
\hline & 8,5 & $\begin{array}{l}\mathrm{NaOH}(\mathrm{pH}=14) \\
\mathrm{Na}_{2} \mathrm{CO}_{3}(\mathrm{pH}=10) \\
\mathrm{NaHCO}_{3}(\mathrm{pH}=7,5\end{array}$ & 7,5 & & $\begin{array}{l}* * \\
20 \\
25\end{array}$ \\
\hline & 13,0 & $\begin{array}{l}\mathrm{NaOH}(\mathrm{pH}=14) \\
\mathrm{Na}_{2} \mathrm{CO}_{3}(\mathrm{pH}=10) \\
\mathrm{NaHCO}_{3}(\mathrm{pH}=7,5)\end{array}$ & 5,0 & & $\begin{array}{l}20 \\
30 \\
10\end{array}$ \\
\hline & 8,94 & $\begin{array}{l}\mathrm{NaOH}(\mathrm{pH}=14) \\
\mathrm{Na}_{2} \mathrm{CO}_{3}(\mathrm{pH}=10) \\
\mathrm{NaHCO}_{3}(\mathrm{pH}=7,5)\end{array}$ & 1,0 & & $\begin{array}{l}* * \\
35 \\
33\end{array}$ \\
\hline & 10,65 & $\begin{array}{l}\mathrm{NaOH}(\mathrm{pH}=14) \\
\mathrm{Na}_{2} \mathrm{CO}_{3}(\mathrm{pH}=10) \\
\mathrm{NaHCO}_{3}(\mathrm{pH}=7,5)\end{array}$ & 2,0 & & $\begin{array}{l}30 \\
50 \\
70\end{array}$ \\
\hline & 6,5 & $\begin{array}{l}\mathrm{NaOH}(\mathrm{pH}=14) \\
\mathrm{Na}_{2} \mathrm{CO}_{3}(\mathrm{pH}=10) \\
\mathrm{NaHCO}_{3}(\mathrm{pH}=7,5)\end{array}$ & 0,8 & & $\begin{array}{l}30 \\
55 \\
95\end{array}$ \\
\hline
\end{tabular}

* rendimento isolado; ${ }^{* *}$ muitos produtos

Um outro estudo interessante demonstra que a reação de adição de tiofenol a nitro-olefinas em meio aquoso leva aos $\beta$ nitro-sulfetos correspondentes em rendimentos que variam de $58-95 \%$ (Esquema 32$)^{58}$. Para o caso da nitro-olefina cíclica 1nitro-ciclo-hexeno, o único produto observado foi o cis-1-nitro2-(feniltio)-ciclo-hexano em $70 \%$ de rendimento.<smiles>[R]C=C(C)[N+](=O)[O-]</smiles>

\begin{tabular}{l|c|c|l}
\hline R & tempo & $\%$ & anti / sin \\
\hline $\mathrm{Ph}$ & $30 \mathrm{~min}$ & 95 & $73 / 27$ \\
$\mathrm{Et}$ & $40 \mathrm{~min}$ & 70 & $80 / 20$ \\
$\mathrm{i}-\mathrm{Pr}$ & $2 \mathrm{~h}$ & 58 & $38 / 62$
\end{tabular}

Esquema 32. Adição de Michael de tiofenol a (E)-nitro oleofinas.
É interessante apontar a síntese da tricetona (6), sem catálise básica, a partir da adição conjugada de 2-metil-1,3-ciclopentanona à metilvinilcetona (Esquema 33$)^{59-61}$. O composto obtido pode ser empregado na síntese de anéis fundidos.

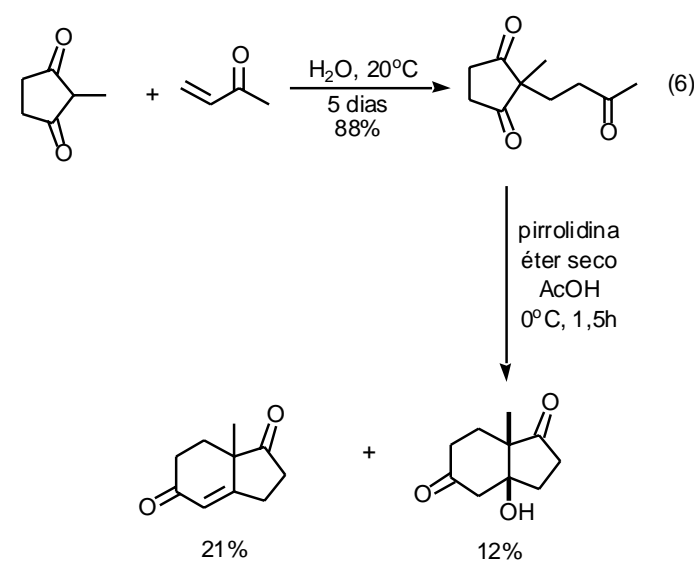

Esquema 33. Adição de Michael de 2-metil-1,3-ciclo-pentanona à metil-vinil-cetona em meio aquoso neutro. 
Não só carbânions foram usados como nucleófilos em adições 1,4 em meio aquoso, mas também fosfinas ${ }^{62,63}$ e piridinas ${ }^{64}$. Lampert e colaboradores estudaram a reação do tipo Michael de fosfinas solúveis em água a alquenos e alquinos ativados ${ }^{62,63}$. A reação se mostrou muito útil para obtenção de compostos deuterados em posições específicas quando realizada em água deuterada (Esquema 34).

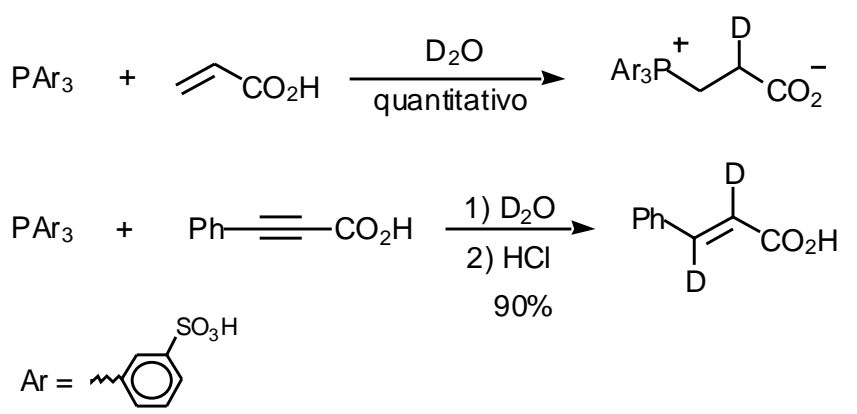

Esquema 34. Adição de fosfinas a alquenos e alquinos ativados.

Luche et al demonstraram que haletos de alquilas reagem com aldeídos e cetonas $\alpha, \beta$-insaturados, levando aos produtos de adição quando na presença de zinco - cobre em água ou solventes duplos (Esquema 35) ${ }^{65-67}$.
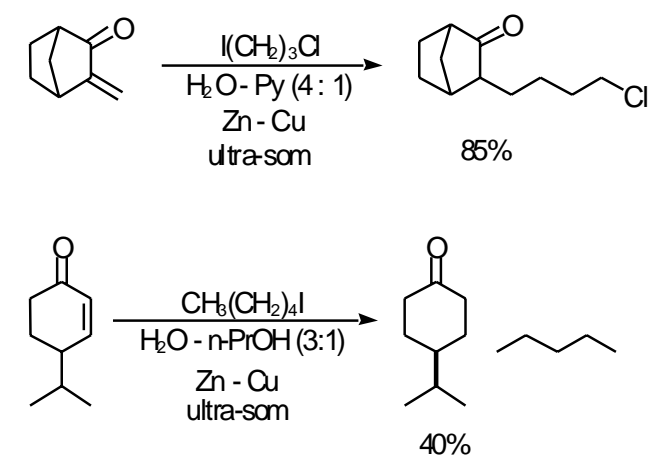

Esquema 35. Adição conjugada de haletos de alquila na presença de $Z n$.

Blanchard et $a l^{68}$ aproveitaram esta metodologia para adicionar unidades de carboidratos e derivados de amino-ácidos a várias olefinas ativadas. Eles observaram também que o uso de ultra-som pode ser substituído por uma agitação vigorosa (Esquema 36 ).
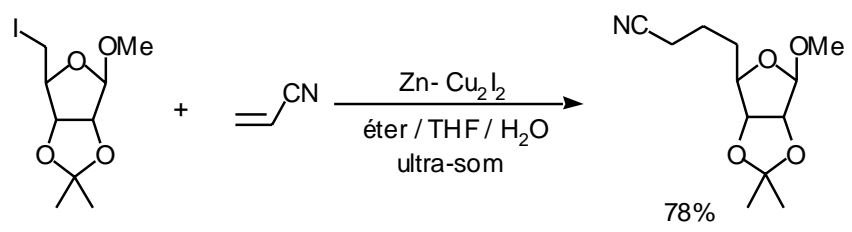

Esquema 36. Adição de resíduo de carboidrato a acrilonitrila.

Uma reação relacionada com a adição de Michael, conhecida como reação de Baylis-Hillman, também foi estudada em meio aquoso mostrando uma aceleração. A reação de benzaldeído com acrilonitrila catalisada por DABCO leva de 7 a $8 \mathrm{~h}$ em água, 34h em metanol, $48 \mathrm{~h}$ em N-metil-acetamida, e 3 a 5 dias em THF ou tolueno.Um aumento ainda maior da constante de velocidade da reação é observado com a adição de iodeto de sódio ou lítio ao meio aquoso, o que sugere que o efeito hidrofóbico esteja envolvido ${ }^{69}$ (Esquema 37).

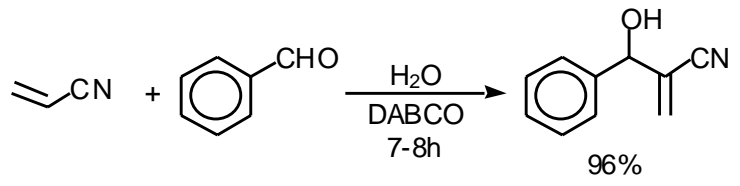

DABCO = 1,4-diazabiciclo[2.2.2]octano

Esquema 37. Reação de Baylis-Hilman.

\section{Oxidações e Reduções}

Muitas oxidações clássicas são feitas em meio aquoso, usando como reagentes oxidantes permanganato de potássio, periodato de sódio, hipoclorito de sódio ou cálcio ${ }^{1}$. Este solvente é bastante conveniente devido à solubilidade destes oxidantes. No entanto, há casos onde o uso de água como solvente tem especial efeito comparado a solventes orgânicos.

Epoxidações de alquenos por perácidos podem ser realizadas prontamente em solventes não polares como diclorometano. Argumenta-se que solventes capazes de formar ligações hidrogênio podem retardar a reação, interferindo com a ligação hidrogênio intramolecular dos perácidos. Porém, foi observado que a reação de alquenos simples com ácido m-cloroperbenzóico (AMCPB) em solução aquosa de bicarbonato $(\mathrm{pH}$ 8,3 ) é rápida à temperatura ambiente ${ }^{70}$.

Uma extensão interessante desta metodologia envolve a epoxidação de álcoois poliolefínicos por perácidos. Estas reações não costumam apresentar quimiosseletividade em meio orgânico. No entanto, pode-se observar uma quimiosseletivamente da epoxidação por ácido monoperftálico (AMPF) em água, quando o pH do meio é controlado (Esquema 38) ${ }^{71}$.

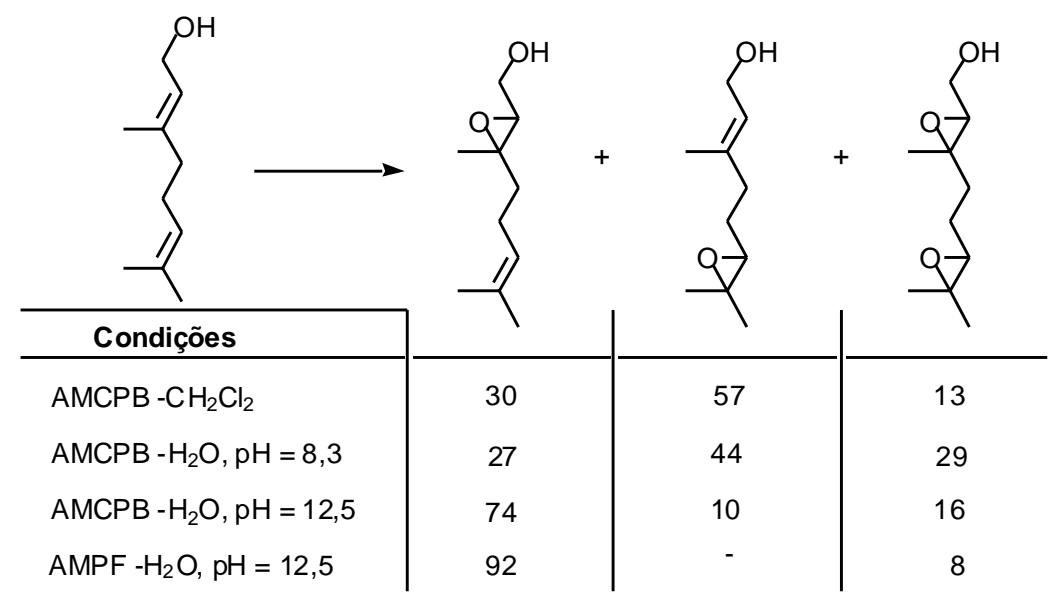

Esquema 38. Quimiosseletividade nas reações de epoxidação. 
Oxidações de Baeyer-Villiger de pinanonas, que são pouco reativas ou levam com dificuldade às lactonas esperadas em solventes orgânicos, têm sido efetuadas em meio aquoso (Esquema 39$)^{72}$.

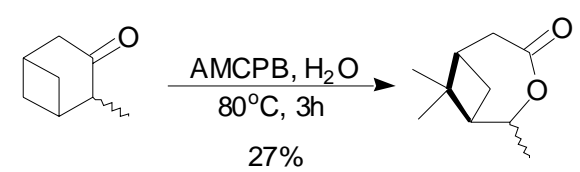

Esquema 39. Oxidação de Baeter-Villiger de pinanonas.

A oxidação de compostos carbonílicos $\alpha$-substituídos com grupos eletroatratores pode ser realizada em solução de hipoclorito de sódio aquoso sem necessidade de um co-solvente, sendo que a utilização de ultra-som pode acelerar a reação ${ }^{73}$ (Esquema 40).

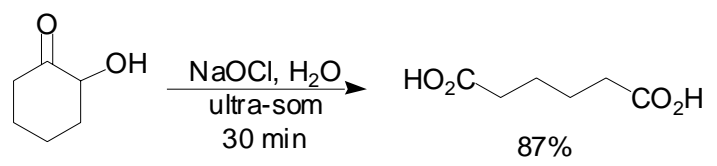

Esquema 40. Oxidação com hipoclorito de sódio sem necessidade de um co-solvente.

Água também tem sido usada como solvente em reduções de compostos orgânicos. Em muitos casos, observa-se uma grande diferença de comportamento em reações promovidas neste solvente quando comparada a solventes orgânicos. Como exemplo, temos a redução do ácido 3,8-nonadienóico por hidrogênio catalisada por um complexo de ródio. Essa reação mostra grande dependência do solvente no que diz respeito à quimiosseletividade (Esquema 41) ${ }^{74}$.

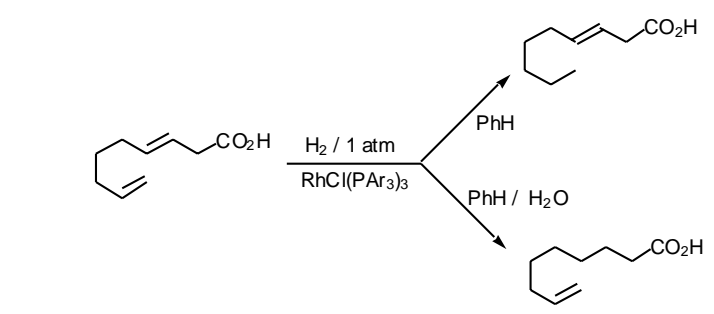

\begin{tabular}{l|c|c|c|c}
\hline \multicolumn{1}{c}{ Condiçóes } & Rend (\%) & ác. 3-nonenóico & ác. 8-nonenóco & ác. nonenóco \\
\hline $\mathrm{PhH} / 4 \mathrm{~h}$ & 89 & 57 & 12 & 24 \\
\hline $\mathrm{PhH} / \mathrm{H}_{2} \mathrm{O}(5: 10) / 2 \mathrm{~h}$ & 90 & 0,7 & 85 & 8
\end{tabular}

Esquema 41. Regiosseletividade nas reações de hidrogenação catalisadas por ródio.

Um aspecto interessante neste caso é a utilização de ligantes quirais solúveis em água. Por exemplo, uma imina proquiral pode ser hidrogenada utilizando-se catalisadores quirais de ródio levando ao produto em excessos enantioméricos acima de $96 \%$ (Esquema 42) $)^{75,76}$.

\section{Reações em Água Superaquecida}

Reações em água superaquecida são encontradas na literatu$\mathrm{ra}^{8,24,77,78}$, como a síntese de 3-metil-2-ciclo-penteno-1-ona em $65 \%$ de rendimento ${ }^{8}$, partindo de 2,5-dimetil-pirrol em água superaquecida $\left(250^{\circ} \mathrm{C}\right)$ por 5 dias (Esquema 43 ).

Recentemente, An J. e colaboradores ${ }^{77}$ estudaram diversas reações em água superaquecida utilizando um reator de microondas pressurizado (RMP) ou uma autoclave (AC) de aquecimento convencional (Esquema 44).

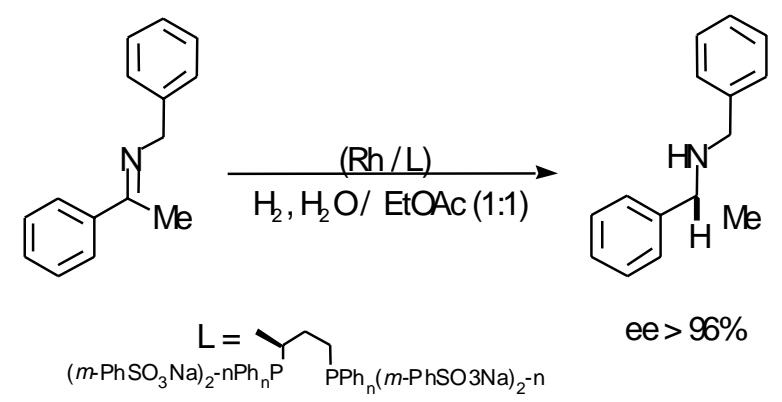

Esquema 42. Utilização de um catalisador assimétrico de ródio para hidrogenação.

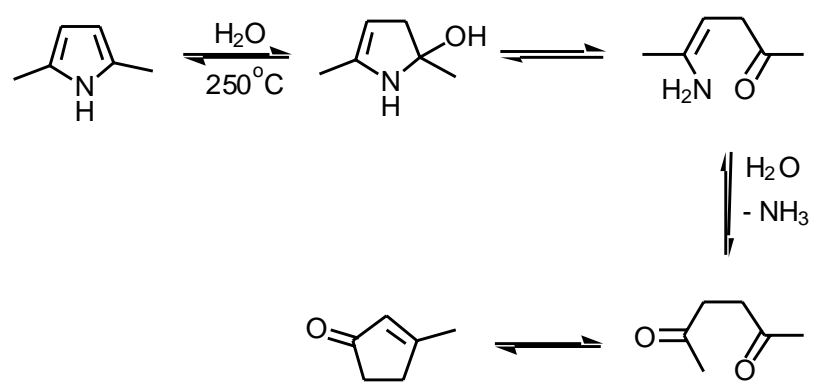

Esquema 43. Reação de 2,5-dimetil-pirrol em águas superaquecidas.

(a) Isomerização da carvona

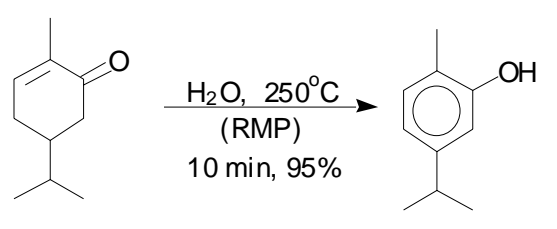

(b) Rearranjo do 1-eten il-1-ciclo-hexanol

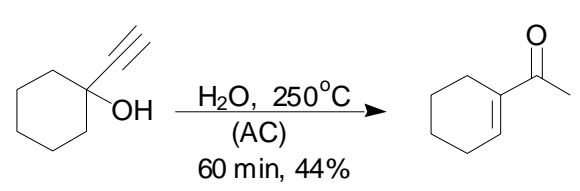

Esquema 44

O 2,4,6-trimetil-benzoato de metila pode ser hidrolisado ou descarboxilado em água superaquecida, dependendo do meio reacional $^{78}$ (Esquema 45).

Compostos muito estáveis sofrem hidrólise em meio aquoso à altas temperaturas sem necessidade de catalisadores. Estas reações podem ser muito úteis no que diz respeito aos aspectos ambientais. Polietilenotereftalato, nylon 6 e 66, poliuretanos, policarbonatos e outras fibras sintéticas podem ser hidrolisadas em meio aquoso neutro à $200-300^{\circ} \mathrm{C}$ aos seus monômeros (Esquema 46) ${ }^{8}$.

\section{Outras Reações}

As reações apresentadas anteriormente são bem representativas para demonstrar o potencial do uso de água como solvente em síntese orgânica. No entanto, neste ítem, são apresentadas algumas outras reações que vêm sendo estudadas em meio aquoso, demonstrando que a diversidade de reações capazes de serem promovidas neste solvente vem aumentando. 


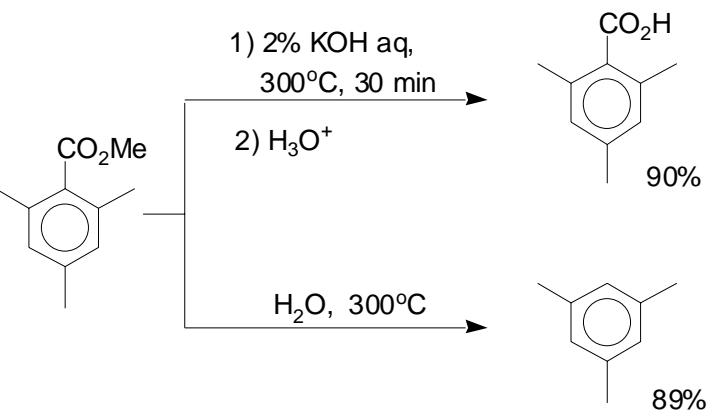

Esquema 45. Reação 2,4,6-trimetil-benzoato de metila em água superaquecida.

(a) Hidrólise do Polietilenotereftalato

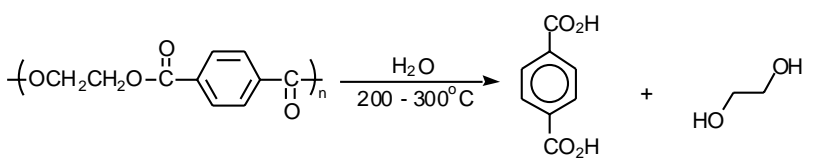

(b) Hidrólise de espuma de poliuretanos

$\stackrel{\text { II }}{\mathrm{H}-\mathrm{Ar}-\mathrm{N}} \underset{\mathrm{H}}{\prod_{\mathrm{O}}} \mathrm{O}-\mathrm{R}-\mathrm{O} f_{\mathrm{n}} \frac{\mathrm{H}_{2} \mathrm{O}}{200-300^{\circ} \mathrm{C}} \mathrm{CO}_{2}+\mathrm{H}_{2} \mathrm{~N}-\mathrm{Ar}^{-\mathrm{NH}_{2}}+\mathrm{HO}-\mathrm{R}-\mathrm{OH}$

Esquema 46

Um exemplo interessante é o acoplamento pinacol, que pode ser feito em água na presença de alumínio ou magnésio. Uma vantagem é a baixa ou nenhuma formação do produto de redução da carbonila (Esquema 47) ${ }^{79,80}$.

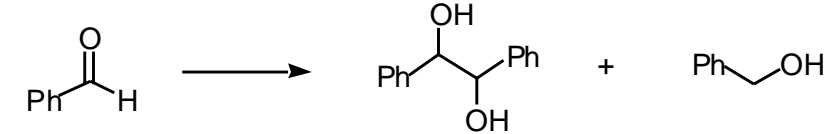

\begin{tabular}{l|c|c}
\hline \multicolumn{1}{c|}{ Condições } & $\%($; / meso) & $\%$ \\
\cline { 2 - 3 } $\mathrm{NaO} / \mathrm{H}_{2} \mathrm{O} / \mathrm{Al} / 2 \mathrm{~h}$ & $89(50 / 50)$ & 0 \\
$\mathrm{NH}_{4} \mathrm{Cl} / \mathrm{H}_{2} \mathrm{O} / \mathrm{Mg} / 90 \mathrm{~h}$ & $95(40 / 50)$ & 5
\end{tabular}

Esquema 47. Acoplamento de Pinacol.

Compostos $\beta$-amino-carbonilados podem ser preparados em meio aquoso através da reação do tipo Mannich. A reação é eficientemente catalisada por ácido dodecilbenzenossulfônico (Esquema 48) ${ }^{81}$.

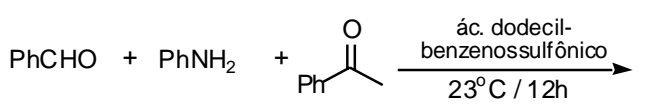

Esquema 48. Reação do tipo Marinch.

A hidroformilação já foi implementada em escala industrial. A reação de propeno com monóxido de carbono para produzir butiraldeído pode ser feita em meio aquoso heterogêneo, onde o catalisador de ródio está dissolvido na água. O processo pertence a Ruhrchemie/Rhône-Poulenc (Esquema 49) ${ }^{82}$.
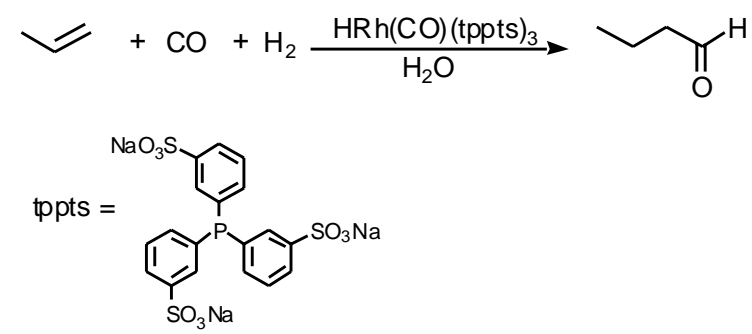

Esquema 49. Processo de Ruhrchemie/Rhone-Poulene.

\section{CONCLUSÕES}

O crescente número de artigos descrevendo as características e utilização da água como solvente nos leva à conclusão que esta pequena molécula ainda não revelou todas as suas propriedades fascinantes. Por outro lado, já foram demonstradas inúmeras possibilidades de avanço em várias áreas da química orgânica, onde diversos tipos de reação comportam-se de maneira diferente quando em solução aquosa, podendo ter rendimentos e velocidades de reação maiores, ou seletividades maiores ou inversas. Até o momento, os efeitos de polaridade, hidrofóbicos e formação de micelas são utilizados para explicar tais comportamentos diferentes.

Os aspectos econômicos e ambientais da utilização de água como solvente sugerem maiores esforços nessa área de pesquisa, onde temos a água como meio reacional barato e de baixos impacto ambiental e toxidez.

\section{REFERÊNCIAS}

1. Lubineau, A.; Augé, J.; Queneau, Y.; Synthesis 1994, 741.

2. King, J. F.; Rathore R.; Lam, J; Guo, Z. R.; Klassen, D. F.; J. Am. Chem. Soc. 1992, 114, 3028

3. Reichardt, C.; In Solvents and solvent effects in organic chemitry, VCH, New York, $2^{\mathrm{a}}$ ed., 1988, p 534.

4. Rideout, D. C.; Brelow. R.; J. Am. Chem. Soc. 1980, 102, 7816.

5. Breslow, R.; Acc. Chem. Res. 1991, 24, 159.

6. Grieco , P. A.; In Organic synthesis in water, Blacki Academic \& Professional, London:, 1998, p310.

7. Li, C. -J.; Chan, T. H.; In Organic reaction in aqueous media, John Wiley \& Sons, Inc, New York, 1997, p198.

8. Katritzky, A. R.; Allin, S. M.; Acc. Chem. Res. 1996, $29,399$.

9. Ahamd-Zadeh Samii, A.; Savignac. A.; Rico, I.; Lattes, A.; Tetrahedron 1985, 41, 3683.

10. Breslow, R.; Maitra, U.; Rideout, D.; Tetrahedron Lett. 1983, 24, 1901.

11. Otto, S.; Engberts, B. F. N.; Tetrahedron Lett. 1995, 36, 2645.

12. Sternbach, D. D.; Rossana, D. M.; J. Am. Chem. Soc. 1982, 104, 5853.

13. Wang, W. B.; Roskamp, E. J.; Tetrahedron Lett. 1992, 33, 7631 .

14. Keay, B. A.; Chem. Commun. 1987, 420.

15. Dols, P. M. A.; Klunder, A. J. H.; Zwanenburg, B.; Tetrahedron 1994, 50, 8515.

16. Brandes, E.; Grieco, P. A.; Garner, P.; Chem. Commun. 1988, 500.

17. Larsen, S. D.; Grieco, P. A.; J. Am. Chem. Soc. 1985, 107, 1768.

18. Waldman, H.; Synthesis 1994, 535.

19. Waldman, H.; Synlett 1995, 133.

20. Lubineau, A.; Augé, J.; Lubin, N.; Tetrahedron Lett. 1991, 32, 7529.

21. De Mattos, M. C. S.; Kover, W. B.; Quim. Nova 1991, 14, 91. 
22. Inoue, Y.; Araki, K.; Shiraishi, S.; Bull. Chem. Soc. Jpn. 1991, 64, 3079

23. Gholami, M. R.; Yangjeh, H.; J. Chem. Reserch (S) 1999, 226.

24. Deroose, F. D.; De Clercq, P. J.; Tetrahedon Lett. 1994, $35,2615$.

25. Copley, S. D.; Knowles, J.; J. Am. Chem. Soc. 1987, 109, 5008.

26. Brandes, E.; Grieco, P. A.; Gajawski, J. J.; J. Org. Chem, 1989, 54, 515

27. Luyten, M.; Keese, R.; Tetrahedron 1986, 42, 1687.

28. Grieco , P. A.; Brandes, E. B.; McCann, S.; Clark, J. D.; J. Org. Chem. 1989, 54, 5849.

29. Lubineau, A.; Auge, J.; Bellanger, N.; Caillebourdin, S.; J. Chem. Soc. Perkin Trans. 1 1992, 13, 1631.

30. Li, C. -J.; Tetrahedron 1996, 52, 5643.

31. Schmid, W.; Whitesides, G. M.; J. Am. Chem. Soc. 1991, $113,6674$.

32. Pétrier, C.; Luche, J. L.; J. Org. Chem. 1985, 50, 910.

33. Li, C. -J.; Chan, T. H.; Tetrahedron Lett. 1991, 32, 7017.

34. McCluskey, A.; Green Chemistry 1999, 1, 167.

35. Li, C. -J.; Zhang, W. -C.; J. Am. Chem. Soc. 1998 , 120, 9102 .

36. Paquette, L. A.; Mitzel, T. M.; Tetrahedron Lett. 1995, 36, 6863.

37. Paquette, L. A.; Rothhaar, R.; J. Org. Chem. 1999, 64, 217.

38. Yang, Y.; Chan, T. H.; J. Am. Chem. Soc. 2000, 122, 402.

39. Kronenberg, M. E.; Havinga, E.; Rec. Trav. Chim. 1965, 17, 979.

40. Lubineau, A.; J. Org. Chem. 1986, 51, 2142.

41. Lubineau, A.; Meyer, E.; Tetrahedron 1988, 44, 6065.

42. Kobayashi, S.; Hachiya, I.; Tetrahedron Lett. 1992, 33, 1625.

43. Kobayashi, S.; Mori, Y.;Nagayama, S.; Manabe, K.; Green Chemistry 1999, 1, 175.

44. Chan, T. H.; Li, C. J.; Wei, Z. Y.; Chem. Commun. 1990, 505.

45. Zhou, J.; Lu, G.; Wu, S.; Synth. Commun. 1992, 22, 481.

46. Mattes, H.; Benezra, C.; Tetrahedron Lett. 1985, 26, 5697.

47. Diana, S. -C. H.; Sim, K. -Y.; Loh, T. -P.; Synlett. 1996, 263.

48. Buonora, P. T.; Rosauer, K. G.; Dai, L.; Tetrahedron Lett. 1995, 36, 4009 .

49. Fringuelli, F.; Pani, G.; Piermatti O.; Pizzo, F.; Tetrahedron 1994, 50, 11499.

50. Denmark, S. E.; Lee, W.; Tetrahedron Lett. 1992, 33, 7729.

51. Balline, R.; Bosica, G.; J. Org, Chem. 1997, 62, 425.

52. Bergmann, E. D.; Ginsburg, D.; Pappo, R.; In Organic Reactions 1959, 10, p 179.

53. Keller, E.; Feringa, B. L.; Tetrahedron Lett. 1996, 37, 1879.
54. Keller, E.; Feringa, B. L.; Synlett 1997, 842.

55. Ballini, R.; Bosica, G.; Tetrahedron Lett. 1996, 37, 8027.

56. Lubineau, A.; Augé, J.; Tetrahedron Lett. 1992, 8073.

57. da Silva, F. M.; Gomes, A. K.; Jones Jr.; J. Can. J. Chem. 1999, 77, 624 .

58. da Silva, F. M.; Jones Jr, J.; J. Braz. Chem. Soc. 2001, $12,135$.

59. Hajos, Z. G.; Parrish, D. R.; J. Org. Chem. 1974, 39, 1612.

60. Harada, N.; Sugioka, T.; Uda, H.; Kurik. T.; Synthesis 1990, 53.

61. Lavallee, J. F.; Deslongchamps, P.; Tetrahedron Lett. 1988, 29, 6033.

62. Larpent, C.; Patin, H.; Tetrahedron 1988, 41, 6107.

63. Larpent, C.; Meignan, G.; Patin, H.; Tetrahedron 1990, $46,6381$.

64. Heo, C. K. M.; Bunting, J. W.; J. Org. Chem. 1992, 57,3570 .

65. Petrier, C.; Dupy, C.; Luche, J. L.; Tetrahedron Lett. 1986, 27, 3149.

66. Luche, J. L.; Allavenda, C.; Tetrahedron Lett. 1988, 29, 5369

67. Luche, J. L.; Allavenda, C.; Petrier, C.; Dupuy, C.; Tetrahedron Lett. 1988, 29, 5373.

68. Blanchard, P.; El Korthi, M. S.: Fourrey, J. L.; RobertGero, M.; Tetrahedron Lett. 1992, 33, 3319.

69. Augé, J.; Lubin, N.; Lubineau, A.; Tetrahedron Lett. 1994, 35, 7947.

70. Fringuelli, F.; Germani, R.; Pizzo, F.; Savelli, G.; Tetrahedron Lett. 1989, 30, 1427.

71. Fringuelli, F.; Germani, R.; Pizzo, F.; Santinelli, F.; Savelli, G.; J. Org. Chem. 1992, 57, 1198.

72. Thomas, A. F.; Rey, F.; Tetrahedron 1992, 48, 1927.

73. Yang, D. T. C.; Zhang, C. J.; Fu, P. P., Kabalka, G. M.; Synth. Commun. 1997, 27, 1601.

74. Okano, T.; Kaji, M.; Isotami, S.; Kiji, J.; Tetrahedron Lett, 1992, 33, 5547.

75. Bakos, J.; Orosz, A.; Heil, B.; Laghmari, M.; Lhoste, P.; Sinou, D.; Chem. Commun. 1991, 1684.

76. Lensink, C.; de Vries, J. G.; Tetrahedron: Asymmetry 1992, 3, 235

77. An, J.; Bagnell, L.; Cablewiski, T.; Strauss, C. R.; Trainor, R. W.; J. Org. Chem. 1997, 62, 2505.

78. Alemán, P. A.; Boix, C.; Poliakoff, M.; Green Chemistry 1999, 1,65 .

79. Mecarová, M.; Toma, S.; Green Chemistry 1999, 1, 257.

80. Bhar, S.; Panja, C.; Green Chemistry 1999, 1, 253.

81. Manabe, K.; Kobayashi, S.; Org. Lett. 1999, 1, 1965.

82. Cornils, B.; Wiebus, E.; Recl. Trav. Chim. Pays-Bas. 1996, 115, 211. 